\title{
Um olhar sobre a Escola Comunitária Municipal Rural "São João Bosco".
}

A look at the Rural Municipal Community School "São João Bosco".

Lucas Silva de Souza

Taysnara Rodrigues Hastenreiter Jardel Zanette Fabem

Resumo: A educação do Campo vem sendo construída pelos movimentos sociais há mais de 20 anos. Neste contexto as Escolas em Alternância tem se destacado em garantir uma educação própria e apropriada para os filhos dos camponeses. Este artigo tem como objetivo relatar a experiência da Escola Comunitária Municipal Rural "São João Bosco", localizada na comunidade Dezoito, Município de Jaguaré, ES, enfatizando o seu processo organizacional, os instrumentos pedagógicos realizados na escola, práxis, currículo e avaliação. Esta vivência permitiu visualizar a importância dessa escola para a comunidade local e a contribuição desses conhecimentos práticos e teóricos para os agricultores, tendo em vista o elo que existe entre Família - Monitor - estudante.

Palavras - Chave: Educação do Campo. Alternância. Estudante

Summary: Rural education has been built by social movements for over 20 years. In this context, the Alternating Schools have stood out in ensuring their own and appropriate education for the children of the peasants. This article aims to report the experience of the Municipal Rural Community School "São João Bosco", located in the Dezoito community, Municipality of Jaguaré, ES, emphasizing its organizational process, the pedagogical instruments carried out in the school, praxis, curriculum and evaluation. This experience allowed us to visualize the importance of this school for the local community and the contribution of this practical and theoretical knowledge to farmers, in view of the link that exists between Family - Monitor - student.

Key- Words: Rural Education. Alternation. Student.

Vários debates coletivos são realizados a cerca da Educação do Campo, buscando reflexões sobre as questões e as possibilidades dessa educação e as tendências da transformação da escola "DO" "e "NO" campo juntamente com os processos pedagógicos trabalhados. Para melhor análise e compreensão da forma escolar, nas escolas do campo, é necessário conhecer os espaços em que a Educação do Campo e a pedagogia da Alternância vêm sendo praticada.

A Escola Comunitária Rural Municipal "São João Bosco" (ECORM) está localizada na Comunidade Dezoito, Zona rural, Município de Jaguaré, Estado do Espírito Santo. Neste sentido esta proposta nos permite olhar dentro das escolas do Campo possibilitando-nos uma analise e reflexão, em relação aos processos pedagógicos desenvolvidos dentro do ambiente escolar. 
O texto trará elementos relacionados à forma escolar, juntamente com os processos organizativos, planejados e trabalhados na escola; elementos referentes à formação curricular, conteúdos trabalhados, relações entre as disciplinas, processos avaliativos desenvolvidos. Isto foi possível através de diálogos com sujeitos que atuam nos processos organizativos da escola (monitores, coordenadores e estudantes) diante da observação e referências teóricas a cerca da Educação do Campo.

A luta pela escola comunitária de São João Bosco se deu, a partir da organização dos agricultores da região no ano de 1990, pois almejavam uma escola diferente da cidade, proporcionando a seus filhos estudarem em um ambiente familiar, dentro da realidade camponesa.

"Pelos agricultores motivados pelo desejo de verem seus filhos e filhas estudando próximo ao ambiente familiar e numa escola que se opusesse ao discurso hegemônico estabelecido. Assim, essa escola não poderia ser nos moldes da escola urbana ou meramente adaptada à realidade rural. Pelo contrário, os agricultores sabiam exatamente que escolas queriam, porque já conheciam a experiência da escola em alternância, pois muitos deles eram exestudantes dessa escola. Eles queriam uma escola "igual" a Escola Família Agrícola de Jaguaré”. (Projeto Político Pedagógico, 2009, p.29.)

O processo de luta pela educação do campo se da nos anos de 1990, pelos movimentos sociais populares rurais/do campo, liderados pelo MST (Movimento dos Sem Terra), que incluem a educação como uma das primeiras demandas (MST, 2005). Podemos perceber que a luta da educação do campo não possui uma concepção concreta, ela vem sendo construída junto aos movimentos sociais, e esse processo vem sendo delineado há mais de 20 anos, (Ribeiro, 2010, p.41).

A educação oferecida aos estudantes campesinos da escola "São João Bosco" é compreendida pelos pais, estudantes e professores como educação do campo, pois acreditam em uma escola transformadora e democrática sendo capaz de analisar e interferir na realidade. Mas para o município é percebida como simplesmente "rural" como o próprio nome da escola já diz Escola Comunitária Rural São João Bosco, isto demonstra a deficiência de 
conhecimentos sobre a luta da educação do campo, nas Secretarias Municipais de Educação.

Assim é possível destacar que as escolas ligadas à Regional das Associações dos Centros Familiares de Formação em Alternância do Espírito Santo (RACEFFAES), organização esta vinculada à via Campesina, que promove a articulação e integração das Escolas Famílias Agrícola (EFA's) e as Escolas Comunitárias Rurais Municipais (ECORM's), e visa manter a unidade político pedagógico com base na pedagogia da alternância, a distinta entidade, oferece cursos de formação que possibilita aos professores estudo e reflexão da educação do campo, ou seja, a formação continuada de professores.

A educação do campo, que tem sido tratada como educação rural na legislação brasileira, tem um significado que incorpora os espaços das florestas, da pecuária, das minas e da agricultura, mas o ultrapassa ao acolher em si os espaços pesqueiros, caiçaras, ribeirinhos e extrativistas. O campo, nesse sentido, mais do que um perímetro não urbano, é um campo de possibilidades que dinamizam a ligação dos seres humanos com a própria produção das condições de existência social e com as realizações da sociedade humana (In: Arroyo, Caldart, Molina, 2011, p.176).

A Escola Comunitária Rural São João Bosco trabalha na modalidade da Pedagogia da Alternância, atendendo as séries finais do Ensino Fundamental, que compreende do $6^{\circ}$ ao $9^{\circ}$ ano, deste modo duas turmas estudam na escola durante uma semana, denominada "sessão escolar" e outras duas permanecem em casa no conjunto da família, denominado "Estadia" e assim sucessivamente, realizam essa alternância entre o meio familiar e o escolar, garantindo a práxis entre a teoria e a prática. É importante ressaltar que dentro da estrutura organizacional das escolas em alternância, os ciclos maiores, coordenam os ciclos menores, a fim de que os alunos que estão em séries mais avançadas possam ajudar os estudantes que estão nas séries menores, nesse sentido o $8^{\circ}$ ano coordena $\circ 6^{\circ}$ ano, e $\circ 9^{\circ}$ coordena $\circ 7^{\circ}$ ano, garantindo a auto organização dos mesmos, durante o período escolar.

O funcionamento da escola acontece de tal forma que os estudantes chegam à escola às 07: $00 \mathrm{~h}$ da manhã e permanecem na escola durante o dia, 
de forma integral, com aulas, atividades práticas e organizativas, e retornando para as suas famílias as 17: $00 \mathrm{~h}$.

Ao longo dos anos a escola atendeu filhos de camponeses que trabalham com a família na propriedade e meeiros, mas ao passar do tempo com o aumento do monocultivo do café, chegam à comunidade trabalhadores de outros Estados, a fim de trabalharem nas fazendas cafeeiras, principalmente na época da colheita, mas de certa forma acabam trabalhando como assalariados e diarista nas fazendas, permanecendo por definitivo na comunidade. Sendo assim a escola também passa a atender os filhos destes trabalhadores.

Com as atuais mudanças no conjunto social das famílias a escola vê a necessidade de reorganizar seus processos pedagógicos, para atender os filhos dos trabalhadores que vivem uma realidade diferente no campo, sendo agricultores assalariados e diarista. Seus filhos não tendo um contato direto com as atividades agropecuárias, a escola percebe a necessidade de desenvolver processos pedagógicos que dêem conta de trazer o educando mesmo estando em alternância para dentro da escola, realizando atividades de lazer e cultura, leitura, informática e também atividades práticas na propriedade da escola.

Com o passar do tempo, famílias se mudaram e outras vieram. A escola já não atende somente estudantes filhos de agricultores (meeiros- $20 \% \mathrm{e}$ proprietários- $70 \%$ ), cerca de $10 \%$ dos estudantes são filhos de trabalhadores rurais empregados nas fazendas da região. Mora nas propriedades ou em torno da escola, na comunidade local, esta começa a se configurar como favela rural. (Projeto Político Pedagógico, 2009, p. 15.)

Para o que bom andamento da escola aconteça é necessário um processo organizativo que dê conta de suprir as necessidades da escola, mas para que isto definitivamente incida é indispensável uma relação MONITOR ESTUDANTE - FAMÍLIA, onde todos os processos organizativos são desenvolvidos de uma forma democrática que se dá em assembléias.

No entanto, cada um possui as suas funções dentro do processo de organização escolar, onde os monitores são responsáveis em transmitir os conhecimentos sistematizados aos estudantes, também se organizam em setores como, agropecuário, pedagógico, administrativo para abranger todas as 
especificidades da escola, e planejarem as atividades a serem executadas, em suas áreas de atuação.

Os três setores: agropecuário, pedagógico e administrativo está intrinsecamente ligado e são interdependentes. O setor administrativo pode ser entendido como aquele que garante o funcionamento dos demais setores. Este dá o suporte necessário para que o setor pedagógico e agropecuário possa cumprir com suas finalidades. (Projeto Político Pedagógico, 2009, p. 113.).

Aos estudantes cabe a tarefa de realizar a auto-organização do Centro Familiar de Formação em Alternância (CEFFA), eles se organizam em associação, e depois se subdividem em equipes de trabalho para realizarem suas tarefas de organicidade, cabe a eles organizar e planejar todos os espaços educativos no qual estão inseridos como, por exemplo: refeitório, sala de aula, tarefas práticas, esporte, etc. Este processo organizativo é de fundamental importância na formação do estudante.

As famílias se organizam em associação tendo presidente e vice, secretário, tesoureiro e fiscais, estes por sua vez correspondem com o funcionamento da gestão escolar, onde são realizadas assembléias que democraticamente se discuta e encaminhem as decisões em prol do bom andamento da escola. Durante o ano letivo as atividades a serem efetuadas são planejadas no conjunto da equipe de monitores, para que isso aconteça são realizados três tipos de planejamento: anual, trimestral e semanal.

O planejamento anual é realizado no inicio do ano letivo, a fim de visualizarem todas as atividades a serem realizadas durante o ano; deste modo as atividades correspondem um calendário anual a ser executado neste período. Para dar seguimento ao planejamento anual é realizado o planejamento trimestral que visualiza as atividades a serem executadas no determinado período, a fim de direcionar a atividade aos determinados responsáveis. 0 planejamento semanal é executado todas as terças-feiras a fim de organizar as disciplinas, e as atividades propostas pelo planejamento anual e trimestral a serem executados na determinada turma.

O currículo escolar proposto pela escola comunitária é construído no coletivo de todas as EFAs e ECORM's ligadas a RACEFFAES, o currículo é 
construído a partir das diferentes realidades nas distintas comunidades camponesas. A partir do currículo pautado na realidade local, são definidos os conteúdos a serem trabalhados nas disciplinas especificas por áreas do conhecimento. De acordo com o corpo pedagógico da ECORM São João Bosco, os conteúdos construídos pelo coletivo das escolas do RACEFFAES não podem ser mudados, apenas acrescentados de acordo com a realidade das diferentes escolas.

De acordo com as orientações construídas coletivamente dentro do conjunto da RACEFFAES, os temas geradores a serem trabalhados durante 0 ano estão propostos no currículo da escola. Em cada trimestre um tema gerador é estudado no coletivo de monitores e estudantes; a partir do tema gerador os estudantes e monitores se juntam em sala de aula para realizar um estudo prévio do tema a ser estudado durante este período. Diante disto, os estudantes se reúnem em grupo para construírem um roteiro de questionamentos, que será levado para serem pesquisados nas famílias, onde este tem por finalidade retirar a maior quantidade de informações da realidade decada sujeito.

O currículo da escola deve ser entendido como a organização dos tempos e espaços do processo educativo, visando a construção de conhecimentos e, na concepção que tem embasado as discussões da educação do campo, envolve a totalidade da escola, para alem dos tempos aulas. (Projeto Político Pedagógico, 2009 p.121).

No retorno à sessão escolar, os estudantes se reúnem em grupos para colocação em comum dos questionamentos pesquisados, ponderando as diferentes realidades de cada sujeito. Na colocação em comum são levantadas as hipóteses, constatações e questionamentos. A partir desta atividade, os monitores se organizam para planejar os aspectos que cada disciplina deve aprofundar, diante disso, estas fazem um maior aprofundamento do tema a ser estudado e da metodologia a ser usada.

Os processos avaliativos da ECORM de São João Bosco exercem um movimento contrario daqueles executados nas escolas tradicionais do Estado. $O$ processo avaliativo da escola comunitária, não está somente ligado à escola ou 
em especifico a sala de aula, o processo de ensino aprendizagem se presta na estadia e na sessão escolar.

"A avaliação é um método de adquirir e processar evidências necessárias para melhorar o ensino e a aprendizagem; inclui uma grande variedade de evidencias que vão alem do exame usual de papel e lápis; é um processo para determinar em que medida os alunos estão se desenvolvendo nos moldes desejados. É um sistema de controle da qualidade, pelo qual será determinada, etapa por etapa do processo ensino-aprendizagem, a efetividade ou não do processo e, em caso negativo, que mudanças devem ser feitas para garantir sua efetividade; é ainda um instrumental da prática educacional para verificar se procedimentos alternativos são ou não igualmente efetivos ao alcance de um conjunto de fins educacionais. Envolve uma coleta sistemática de dados, por meio dos quais se determinam as mudanças que ocorrem no comportamento do aluno, em função dos objetivos educacionais e em que medida estas mudanças ocorrem" (Projeto Político Pedagógico, 2009, p. 77).

A sessão escolar é compreendida como espaço de formação do individuo, onde o monitor é o mediador dos conhecimentos sistematizados a serem transmitidos aos estudantes.

A estadia é abarcada com momentos de relações sociais, onde os estudantes estão presentes na comunidade e no seio familiar, espaço onde os mesmos desenvolvem atividades construídas no coletivo dos estudantes, são direcionadas a fim de serem executadas na comunidade como, por exemplo, o Plano de Estudo.

O processo avaliativo da escola comunitária se dá, em diversas formas sendo elas na sessão escolar e também na estadia como exemplos: Avaliação de habilidade e convivência, Avaliação Coletiva, Avaliação das disciplinas, e Avaliação Final. Estes são instrumentos da Pedagogia da Alternância que demanda uma contribuição das famílias e também dos monitores.

A avaliação de habilidade e convivência é realizada ao final de cada trimestre na sessão escolar, onde os próprios educandos e os acompanhantes de cada turma, ou seja, os professores responsáveis por cada turma constroem 
a avaliação, o sujeito realiza auto-avaliação e são avaliados nas relações sociais, atividades práticas e estudo, na comunidade e na escola.

A Avaliação coletiva é uma atividade que garante a integração por áreas do conhecimento, possuem uma relação entre os conteúdos vivenciais e científicos, a avaliação é construída a parti do Plano de Estudo, ela é realizada em grupo pelos estudantes no período escolar. A avaliação das disciplinas é desempenhada ao final de cada trimestre, a forma de executar a avaliação fica a critério de cada monitor.

Durante o período da sessão escolar ao final de cada semana de estudo, os estudante, professores e funcionários agrupam-se, para efetuar uma avaliação que garanta uma gestão dentro da escola, essa avaliação é denominada de "avaliação de sessão", que visa possibilitar, o amadurecimento do coletivo, discutir os problemas da escola, incentivar o companheirismo entre os estudantes, destacando os pontos positivos e negativos durante aquela semana, e sugerindo encaminhamentos para as sessões futuras.

Ao final de cada ano letivo os estudantes executam uma atividade que é considerada um trabalho de aprofundamento sobre um problema existente na comunidade, tanto no agropecuário, social, econômico, possibilitando então, ao estudante ver, analisar, descrever, observar os seguintes problemas a ser estudada pelos estudantes, esta atividade é conhecida como "Avaliação Final”. Esta avaliação é orientada pelos monitores responsáveis por cada turma, no meio do ano letivo, para que o estudante possa ter tempo em realizar todos os passos de forma eficaz, garantindo uma melhor participação da comunidade e da família neste processo.

Durante o período de inserção na Escola Comunitária Rural Municipal São João Bosco, percebemos o grande potencial em relação à organização do currículo escolar, e os métodos avaliativos, planejamentos que a partir da organização regional da RACEFFAES, é construído no coletivo de todas as EFA's e ECORM's, este processo é de estrema importância na construção da educação própria e apropriada do campo e para o campo. Os processos organizativos da escola se da em âmbito coletivo, pois é neste espaço em que a comunidade e a escola se fazem presente, a fim de organizar o ambiente 
escolar. Acreditamos que este processo nos permite refletir como é importante conhecer e fazer parte desta dinâmica construída no coletivo entre família, estudante e professor.

A partir da prática de inserção na escola, tomamos o uso do Projeto Político Pedagógico da instituição, como um documento norteador da pesquisa, que é de fundamental importância para o bom andamento da escola, e que parte da construção coletiva entre as famílias, a comunidade e os estudantes, garantindo o elo que torna a escola acessível e apropriada para os jovens do campo.

\section{Referências}

ARROYO, Miguel Gonzalez; CALDART, Roseli Salete; MOLINA, Mônica Castagma (Orgs.). Por uma educação do campo. Petrópolis, Rio de Janeiro: Vozes, 2011.

CALDART, Roseli; (org.) Caminhos para transformação da escola. 1. Ed.-Bela Vista, São Paulo: Expressão Popular, 2011.

Projeto Político Pedagógico. Escola Comunitária Rural Municipal "São João Bosco", 2009.

RIBEIRO, Marlene. Movimento Camponês, Trabalho e Educação liberdade, autonomia, emancipação: príncipios/fins da formação humana. 1.Ed.-São paulo: Expressão Popular, 2010.

\section{Sobre os autores}

\section{Lucas Silva De Souza}

lucas.agronomia@hotmail.com

Educador na Escola Municipal Família Agrícola "Jacyra de Paula Miniguite, graduado em Licenciatura em Educação do Campo (Ciências Agrarias) pela UNIOESTE, Cascavel - PR; Especialista em Educação do campo pelas UFSCAR; Mestre em Educação Agrícola pela UFRRJ, Seropédica - RJ.

\section{Taysnara Rodrigues Hastenreiter}

thaysnarah@hotmail.com

Educadora no Centro Integral de Educação Rural de Águia Branca; graduado em Licenciatura em Educação do Campo (Ciências Agrarias) pela UNIOESTE, UFRB, Amargosa - BA. 


\section{Jardel Zanette Fabem}

jardel.fabem@hotmail.com

Educador na Escola Municipal de Ensino Fundamental de Educação Rural Camponesa Conjunto Familiar Agostinho Partelli; graduado em Licenciatura em Educação do Campo (Ciências Agrarias) pela UNIOESTE, Cascavel - PR. 